\title{
Spontaneous Regression of Hepatocellular Carcinoma due to Disruption of the Feeding Artery
}

\author{
Akihiro Okano Masaya Ohana Fusako Kusumi Motoshige Nabeshima \\ Department of Gastroenterology, Tenri Hospital, Tenri, Japan
}

\section{Key Words}

Spontaneous regression $\cdot$ Hepatocellular carcinoma $\cdot$ Ischemia $\cdot$ Feeding artery

\begin{abstract}
We present an unusual case of spontaneous regression of hepatocellular carcinoma (HCC). A 77-year-old man with alcoholic liver cirrhosis presented with a 50-mm tumor in the Couinaud's segment 8 (S8) of the liver, a 15-mm tumor in the S8-7 and 10-mm tumors in the other segments $(\mathrm{S} 4, \mathrm{~S} 6)$. The tumors were diagnosed as $\mathrm{HCC}$ by typical imaging findings and elevated serum alpha-fetoprotein (AFP, $1,825.0 \mathrm{ng} / \mathrm{ml}$ ) and protein induced by vitamin $\mathrm{K}$ absence II (PIVKA II, 3,043 mAU/ml). One month later, AFP and PIVKA II decreased to 51.1 $\mathrm{ng} / \mathrm{ml}$ and $411 \mathrm{mAU} / \mathrm{ml}$, respectively, and the $50-\mathrm{mm}$ tumor in the S8 became small and completely necrotic on angiography and computed tomography arteriography without any treatment. On the other hand, the $15-\mathrm{mm}$ tumor in the S8-7 decreased in size to $10 \mathrm{~mm}$ and received blood supply from the right posterior superior arteries (A7). The other 10-mm tumors remained. Ischemia of the tumors due to disruption of the feeding artery (A8) might have induced tumor regression in the present case.
\end{abstract}

\section{Introduction}

Spontaneous regression (SR) of malignant tumor was first defined by Cole and Everson [1] as complete or partial clearance of malignant cells in the absence of any specific treatment, particularly antineoplastic chemotherapy or surgical resection. It is an extremely rare phenomenon and its incidence is estimated to be one per 60,000-100,000 cancer patients [2]. SR of malignant tumor has been reported mainly in neuroblastoma, renal cell carcinoma, malignant melanoma, malignant lymphoma, and leukemia. SR of hepatocellular 
Okano et al.: Spontaneous Regression of Hepatocellular Carcinoma due to Disruption of the Feeding Artery

carcinoma (HCC) is an infrequent phenomenon. We report an unusual case of SR of HCC, possibly due to disruption of the feeding artery.

\section{Case Report}

A 77-year-old man with alcoholic liver cirrhosis was referred to our hospital on August, 2010 for workup of hepatic masses incidentally found by abdominal computed tomography (CT). He had no history of hypertension, diabetes mellitus, and atherosclerosis. He had been a regular drinker, consuming approximately $120 \mathrm{~g}$ /day of alcohol every day for 50 years. He had smoked 20 cigarettes per day for 50 years. He took no drugs.

Examination of the head, neck, chest, heart, and extremities was unremarkable. Palmar erythema and vascular spider were noted in the skin. The abdomen was soft and flat, and neither masses nor ascites were palpable. Laboratory examinations showed $\mathrm{Hb}$ of $9.5 \mathrm{~g} / \mathrm{dl}$, platelets of $139,000 / \mathrm{mm}^{3}$, and WBC count of $6,600 / \mathrm{mm}^{3}$. Blood chemistry tests revealed aspartate aminotransferase of $172 \mathrm{IU} / \mathrm{l}$, alanine aminotransferase of $59 \mathrm{IU} / \mathrm{l}, \gamma$-GTP of 461 $\mathrm{IU} / \mathrm{l}$, alkaline phosphatase of $461 \mathrm{IU} / \mathrm{l}$, albumin of $2.9 \mathrm{~g} / \mathrm{dl}$, globulin of $3.9 \mathrm{~g} / \mathrm{dl}$, total bilirubin of $2.6 \mathrm{mg} / \mathrm{dl}$, prothrombin time of $51.7 \%$, and glucose of $102 \mathrm{mg} / \mathrm{dl}$. Serum HBs antigen, HBs antibody, and HCV antibody were negative. Serum alpha-fetoprotein (AFP) was 1,825.0 $\mathrm{ng} / \mathrm{ml}$ (normal $<10 \mathrm{ng} / \mathrm{ml}$ ) and protein induced by vitamin $\mathrm{K}$ absence II (PIVKA II) was $3,043 \mathrm{mAU} / \mathrm{ml}$ (normal $<40 \mathrm{mAU} / \mathrm{ml}$ ). His Child-Pugh score was 8 (Child-Pugh class B).

Abdominal ultrasonography demonstrated a $50-\mathrm{mm}$ hypoechoic mass with a mosaic pattern in the right anterior superior segment of the liver (Couinaud's segment 8, S8) and a 15-mm hypoechoic mass in the S8-7. Dynamic contrast-enhanced CT scan showed a partially hypervascular tumor with necrotic area in the S8 and a hypervascular tumor in the S7-8 (fig. 1) and 10-mm hypervascular tumors in the other segments (S6 and S4) on August, 2010. The findings of the above high level of tumor markers and imaging examinations were consistent with HCC. He did not receive any further treatment for HCC including herbal medicine and stopped drinking alcohol for one month after the diagnosis of HCC. There had been no accidental events including fever and pain for several months. One month after the diagnosis, AFP and PIVKA II spontaneously decreased to $51.1 \mathrm{ng} / \mathrm{ml}$ and $411 \mathrm{mAU} / \mathrm{ml}$, respectively. The $50-\mathrm{mm}$ mass in the $\mathrm{S} 8$ decreased to $30 \mathrm{~mm}$ and became completely necrotic on CT arteriography (CTA) (fig. 2) on September, 2010. The 15-mm mass in the S8-7 diminished to $10 \mathrm{~mm}$ and was described as an enhanced lesion on CTA (fig. 2). Hepatic angiography disclosed no tumor stain and occlusion in the right anterior superior arteries (A8) (fig. 3a, b). Tumor stains were noted in the A7 (the above mass in the S8-7) (fig. 3c), A6, and A4. The hypervascular tumors were treated by transcatheter arterial chemoembolization (TACE) using an emulsion of $3 \mathrm{ml}$ lipiodol and $30 \mathrm{mg}$ epirubicin with gelfoam. Serum AFP and PIVKA II decreased to the normal range $(5.7 \mathrm{ng} / \mathrm{ml}$ and $37 \mathrm{mAU} / \mathrm{ml}$, respectively) on October, 2010.

Unfortunately, the tumor regression was not confirmed histologically. After that, the tumor with SR in the S8 completely became scar without local recurrence. Six and 16 months after the first treatment, several new recurrent tumors that measured $10 \mathrm{~mm}$ were detected in the other segments of the liver. TACE was performed to the recurrences. AFP and PIVKA II have remained normal in spite of the recurrences. 
Okano et al.: Spontaneous Regression of Hepatocellular Carcinoma due to Disruption of the Feeding Artery

\section{Discussion}

We report herein a rare case of SR of HCC. For diagnosis of SR, it is important to prove the presence of malignant cells morphologically. The limitation of the present case study is that this case was not histologically proven before SR. However, the findings of the abdominal CT (fig. 1, fig. 2) and the marked elevation of serum AFP and PIVKA II level were useful for the diagnosis of HCC.

In the previous reports of SR of HCC, clinical characteristics vary widely. Tumor regression, either partial or complete, has been reported in various patients. There has been no common tendency about the number and size of tumor, the level of tumor markers, extrahepatic metastases, and causative liver disease [3]. The causative factors and mechanisms leading to SR of HCC are unclear, although two possible causes have been considered in previous literature [4].

In the first place, ischemia has been thought to be the major cause of subsequent necrosis of the oxygen-sensitive malignancy. Because of the hypervascular nature of HCC, an important factor might be an insufficient blood supply to the tumor, possibly due to disruption of the feeding artery [5, 6], portal vein tumor thrombus [7, 8], deprivation of oxygen due to rapid natural tumor growth [8], massive bleeding [9], and poor arterial supply in cirrhotic liver [10].

In the second place, immunological mechanisms might cause SR of HCC. Abstinence from alcohol or smoking $[8,11]$, blood transfusion [12], the use of some herbal medicine [13], withdrawal of anabolic steroids [14], and fever [15] stimulate the production of cytokines such as tumor necrosis factor (TNF) and TNF may play an important role in antitumor activities. Tumor regression has been observed not only in the primary site but also in metastatic regions by systemic effects such as immune responses.

What are the causative factors leading to SR of HCC in the present case? Generally, SR of HCC develops after the above possible events; however, none of these events could be identified in the present patient. At the first diagnosis, the $50-\mathrm{mm}$ tumor in the S8 was described as a high-, iso-, and low-density lesion at the early phase on dynamic-enhanced CT. At this time, the tumor in the S8 might have already begun to lose arterial blood (A8) and to become necrotic. One month later, the tumor in the S8 spontaneously became small and completely necrotic and the $15-\mathrm{mm}$ tumor in the S8-7 decreased to $10 \mathrm{~mm}$ (fig. 1, fig. 2). Tumor stain was absent in the A8 (fig. 3a, b) and was present in the A7 (fig. 3c) on hepatic angiography. In addition, the tumors in the other segments (S6 and S4) remained the same in size and character. Therefore, disruption of only the feeding A8 may be responsible for this phenomenon. Namely, the tumor in the S7-8 might originally have received blood supply from the A7 and A8 and decreased in size, possibly due to disruption of the feeding A8.

Two mechanisms of local ischemia due to loss of arterial blood supply are speculated: disruption of the feeding artery associated with angiography [5] and arterial thrombosis [6]. The former is due to a case in which, during the procedure of superselective catheterization, severe subintimal injury occurred in the proper hepatic artery [5]. The latter is deduced from a case in which the resected specimen showed arterial thrombus in non-tumor liver tissue [6]. The present case is unique as regards the fact that CT suggested the concern of blood supply (A8) loss by the complete tumor regression in the S8 and the partial regression in the S7-8. However, it is difficult to prove the local effect of deficiency of blood supply (A8) in the present patient. Furthermore, the mechanisms which lead to disruption of the feeding A8 remain unknown. Thrombus might have been transiently formed only in the A8.

Abstinence from alcohol for one month might have improved his immunological function [11]. However, it is difficult to explain the phenomenon by systemic effect of the 
Okano et al.: Spontaneous Regression of Hepatocellular Carcinoma due to Disruption of the Feeding Artery

immunological mechanisms, because the other tumors in the S6 and S4 remained. We assume that a local effect was involved in the mechanism of SR in the present patient.

After all, although the precise mechanism of SR cannot be fully explained in the present case, disruption of the feeding artery might have played a role in this outcome [6]. We consider that the accumulation of clinical data obtained from patients with SR of HCC will contribute to the understanding of this phenomenon.

\section{Disclosure Statement}

There is no conflict of interest.

\section{References}

1 Cole WH, Everson TC: Spontaneous regression of cancers: preliminary report. Ann Surg 1956;144:366-383.

-2 Cole WH: Efforts to explain spontaneous regression of cancer. J Surg Oncol 1981;17:201-209.

-3 Oquinena S, Inarrairaegui M, Vila JJ, Alegre F, Zozaya JM, Sangro B: Spontaneous regression of hepatocellular carcinoma: Three case reports and a categorized review of the literature. Dig Dis Sci 2009;54:1147-1153.

-4 Oquinena S, Guillen-Grima F, Inarrairaegui M, Zozaya JM, Sangro B: Spontaneous regression of hepatocellular carcinoma: a systematic review. Euro J Gastroenterol Hepatol 2009;21:254-257.

-5 Takayasu K, Muramatsu Y, Shima Y, Moriyama N, Yamada T, Yoshida T, et al: Necrosis of hepatocellular carcinoma as a result of subintimal injury incurred by hepatic angiography: report of two cases. Am J Gastroenterol 1986;81:979-983.

6 Imaoka S, Sasaki Y, Masutani S, Ishikawa O, Furukawa H, Kabuto T, et al: Necrosis of hepatocellular carcinoma caused by spontaneously arising arterial thrombus. Hepatogastroenterology 1994;41:359-362.

-7 Uenishi T, Hirohashi K, Tanaka H, Ikebe T, Kinoshita H: Spontaneous regression of a large hepatocellular carcinoma with portal vein tumor thrombi: report of a case. Surg Today 2000;30:82-85.

-8 Okano A, Takakuwa H, Nakamura T: Spontaneous regression of diffuse intrahepatic recurrence with portal vein tumor thrombus after resection of hepatocellular carcinoma. Clin J Gastroenterol 2011;4:43-48.

-9 Tocci G, Conte A, Guarascio P, Visco G: Spontaneous regression of a hepatocellular carcinoma after massive gastrointestinal hemorrhage. BMJ 1990;300:641-642.

10 Van Halteren HK, Salemans JM, Peters H, Vreugdenhil G, Driessen WM: Spontaneous regression of hepatocellular carcinoma. J Hepatol 1997;27:211-215.

11 Gottfried EB, Steller R, Paronetto F, Lieber CS: Spontaneous regression of hepatocellular carcinoma. Gastroenterology 1982;82:770-774.

12 Sato Y, Fujiwara K, Nakagawa S: A case of spontaneous regression of hepatocellular carcinoma with bone metastasis. Cancer 1985;56:667-671.

13 Chien RN, Chen TJ, Liaw YF: Spontaneous regression of hepatocellular carcinoma. Am J Gastroenterol 1992;87:903-905.

14 Johnson FL, Lerner KG, Siegel M, Feagler JR, Majerus PW, Hartmann JR, et al: Association of androgenicanabolic steroid therapy with development of hepatocellular carcinoma. Lancet 1972;2:1273-1276.

15 Jansen PM, van der Pouw Kraan TC, de Jong IW, van Mierlo G, Wijdenes J, Chang AA, et al: Release of interleukin-12 in experimental Escherichia coli septic shock in baboons: relation to plasma levels of interleukin-10 and interferon-gamma. Blood 1996;87:5144-5151. 


\section{Case Reports in Oncology}

\begin{tabular}{l|l}
\hline Case Rep Oncol 2013;6:180-185 \\
\hline DOI: $\underline{10.1159 / 000350682}$ & $\begin{array}{l}\text { C 2013 S. Karger AG, Basel } \\
\text { www.karger.com/cro }\end{array}$ \\
\hline
\end{tabular}

Okano et al.: Spontaneous Regression of Hepatocellular Carcinoma due to Disruption of the Feeding Artery
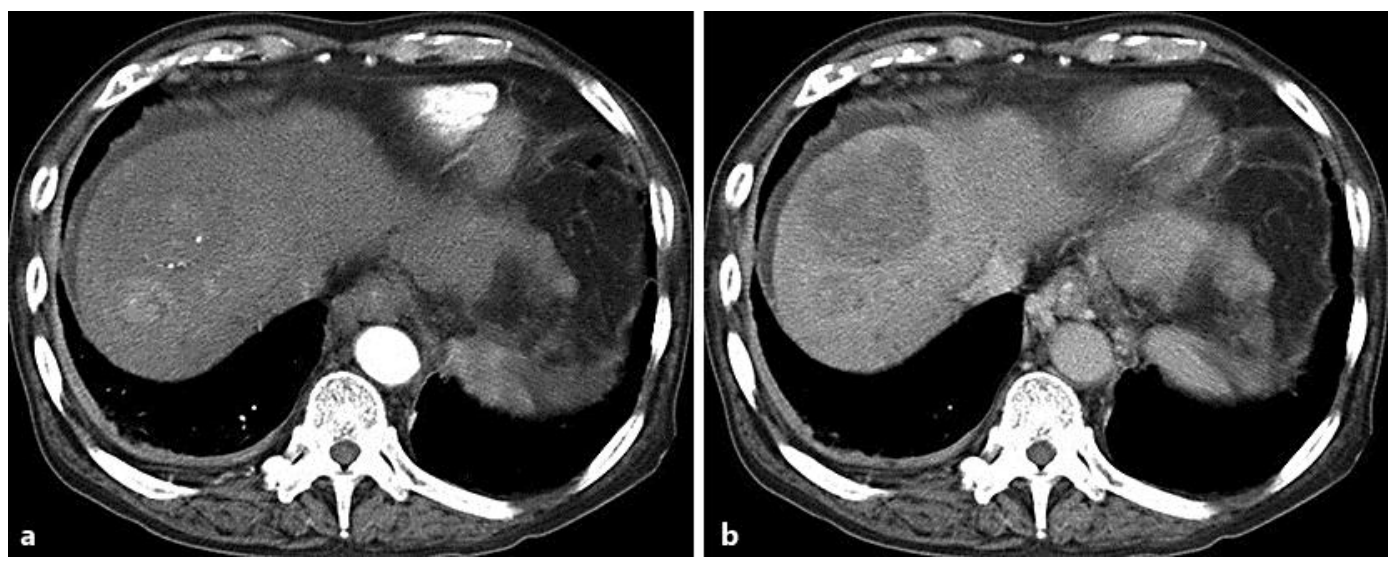

Fig. 1. A 50-mm mass in the S8 and a 15-mm mass in the S7-8 were described as a high-, iso-, and lowdensity lesion and a high-density lesion, respectively, at the early phase (a) and as low-density lesions at the delayed phase (b) on dynamic CT.

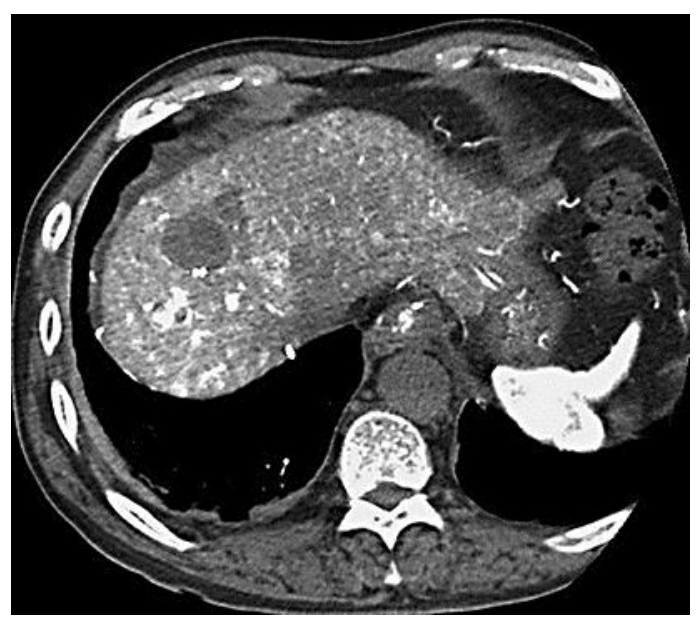

Fig. 2. The mass in the S8 decreased to $30 \mathrm{~mm}$ and was described as a low-density lesion on CTA. The mass in the S8-7 diminished to $10 \mathrm{~mm}$ and was described as a high-density lesion on CTA. 


\section{Case Reports in Oncology}

\begin{tabular}{l|l}
\hline Case Rep Oncol 2013;6:180-185 \\
\hline DOI: $\underline{10.1159 / 000350682}$ & $\begin{array}{l}\text { C 2013 S. Karger AG, Basel } \\
\text { www.karger.com/cro }\end{array}$ \\
\hline
\end{tabular}

Okano et al.: Spontaneous Regression of Hepatocellular Carcinoma due to Disruption of the Feeding Artery

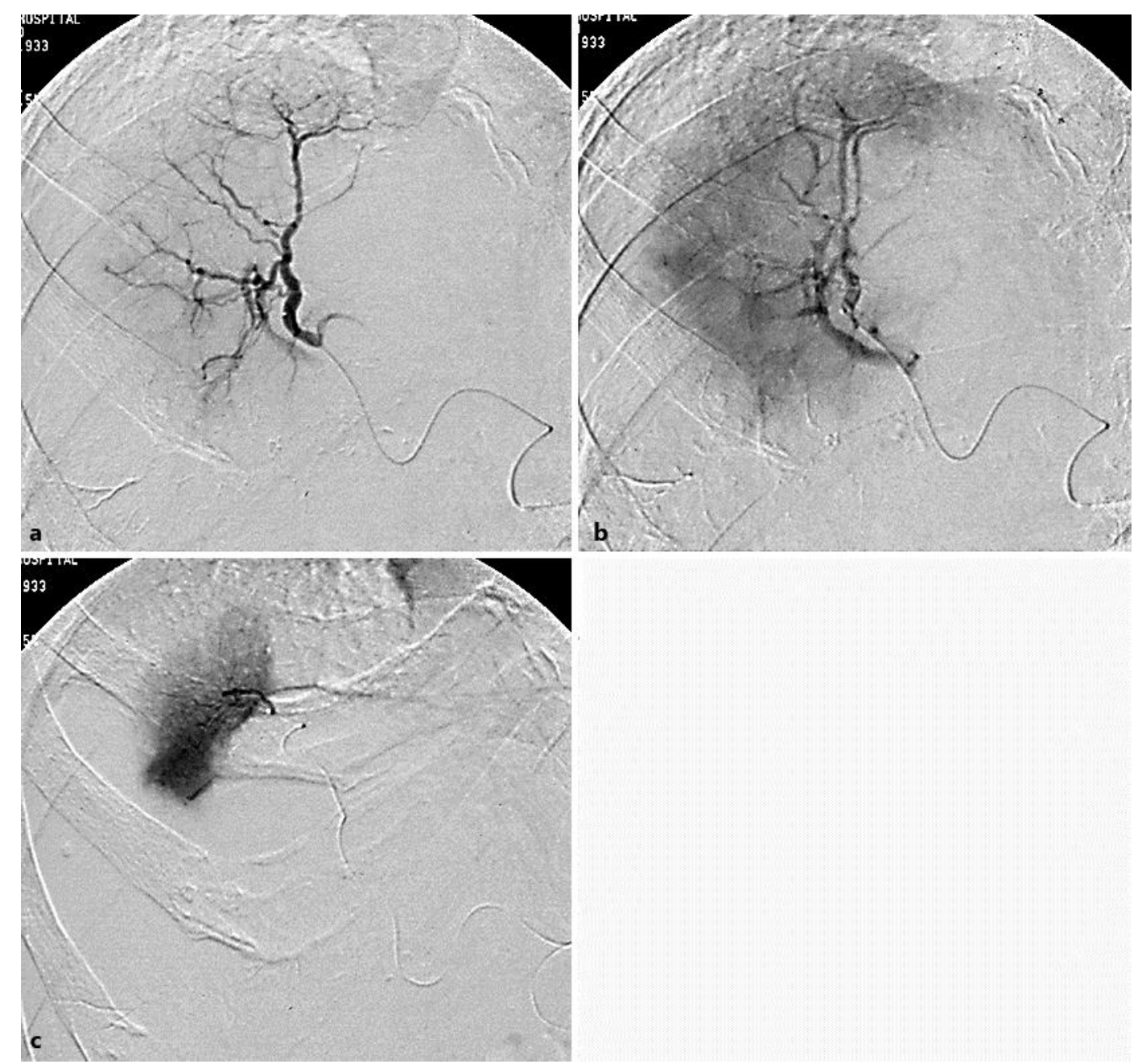

Fig. 3. Tumor stain and occlusion were absent in the A8 $(\mathbf{a}, \mathbf{b})$ on the right anterior arteriography of the liver. There was tumor stain in the A7 (c) on the selective right posterior superior arteriography of the liver. 